\title{
Clinical Study on Autosomal Dominant Polycystic Kidney Disease among South Indians
}

\author{
P. Veeramuthumari*, W. Isabel \\ PG \& Research Department of Zoology \& Biotechnology, Lady Doak College, Madurai, India. \\ Email: *muthusdream@gmail.com,*muthusdream@yahoomail.com
}

Received January $14^{\text {th }}, 2013$; revised March $3^{\text {rd }}, 2013$; accepted April $16^{\text {th }}, 2013$

Copyright (C) 2013 P. Veeramuthumari, W. Isabel. This is an open access article distributed under the Creative Commons Attribution License, which permits unrestricted use, distribution, and reproduction in any medium, provided the original work is properly cited.

\begin{abstract}
Autosomal dominant polycystic kidney disease (ADPKD) is a commonly inherited disorder in humans, with a frequency of 1 in 100 in the general population. ADPKD is caused by mutations in PKD1 gene (85\%) located on human chromosome 16p13.3; Mutations in the PKD2 gene contribute to 15\% of ADPKD incidence and is located on human chromosome 4q21 - 23. A total of hundred ADPKD patients and age and sex matched healthy individuals were selected for the study. The study was aimed to evaluate the prevalence of ADPKD, lipid profile and level of calcium (Ca), sodium $(\mathrm{Na})$, iron $(\mathrm{Fe})$ and potassium $(\mathrm{K})$ in patients with ADPKD and in healthy individuals. The lipid profile was analyzed using commercially available span kit and semiautoanalyzer (Erba, Chem 5X). The Ca, Na, Fe and K concentrations were estimated by flame photometry (ELICO, CL 22D) and atomic absorption spectroscopy (ELICO, SL 173) and significant changes were noted at $\mathrm{p}<0.05$. The ADPKD patients were observed to have lipid abnormalities, hyponatremia, cholesterolemia, renal osteodystrophy, cardiovascular problems and anemia. Therefore, the study reveals an association between the lipid profile and $\mathrm{Ca}$, Na, Fe and K levels with ADPKD among South Indian population.
\end{abstract}

Keywords: Polycystic Kidney Disease; Hyponatremia; Renal Osteodystrophy; Anemia

\section{Introduction}

The polycystic kidney diseases (PKD) are the most common hereditary nephropathies and are reported to result in end-stage renal disease (ESRD) by the age of 60 - 70 yr [1-4]. Polycystic kidney diseases are primarily characterized by the progressive development of renal multiple epithelial cysts in both the kidneys. Polycystic kidney disease is broadly divided into 2 forms, autosomal recessive polycystic kidney disease (ARPKD) and autosomal dominant polycystic kidney disease (ADPKD) [4-8]. The diseases are caused by mutation either in PKD1 (85\%) or PKD2 (15\%) and PKD3 (rare) genes [7-12].

Autosomal dominant polycystic kidney disease (ADP$\mathrm{KD}$ ) occurs worldwide in all races. ADPKD disease is one of the most commonly inherited conditions in humans with an incidence of 1:400 to 1:1000 [1,7,13,14]. It is genetically heterogeneous with two genes being identified, PKD1 (16p13.3) and PKD2 (4q21) [11,15,16]. The proteins encoded by PKD1 and PKD2 are called polycystin 1 and polycystin $2[10,17,18]$, which interact with each other in the primary cilia of renal epithelial cells

"Corresponding author. and participate in complex signal transduction pathways, which might be involved in mechanic/chemosensory functions and have some role in cell proliferation and maturation $[10,16]$. Fibrocystin is defective in autosomal recessive PKD [5,6,19,20].

The common complications noted in polycystic kidney disease include hypertension, macroscopic hematuria, urinary tract infection, renal calculi, diabetes mellitus, renal osteodystrophy, cardiac valve abnormalities, anemia, hernia of the anterior abdominal wall and cerebral berry aneurysm [21].

The impact of lipid abnormalities on renal function have been evaluated in various studies [22-24]. Common abnormalities include an elevation of serum or plasma triglycerides (TGL), a decrease in the high-density lipoprotein (HDL) cholesterol, and elevation in low-density lipoprotein (LDL) cholesterol and marked oxidation of LDL cholesterol [22]. Hypertriglyceridemia is the most common plasma lipid abnormality in patients with renal failure $[25,26]$. Dyslipdemia is a common complication of progressive kidney disease which also contributes to high cardiovascular morbidity and mortality of renal disease patients [27]. 
The Polycystins have regulatory role in ion transport. The polycystic epithelial cells have been reported to show propensity to secrete solutes and fluid rather than absorbing them [28], which would be directed to the regulation of ion permeability and possibly the misstep that initiates cytogenesis in patients with autosomal dominant polycystic kidney disease (ADPKD) [29].

In patients with $\mathrm{PKD}$, both genetic and biochemical studies have been conducted in most of the populations worldwide (Caucasians, Japanese, Argentines, Canadian, Egyptian, Chinese, Italian and United States) by different researchers [3,5,6,24-26,30]. However, till now no study is available among south Indian (Madurai) population. Hence, the present study is focused on the lipid profile and the level of certain elements like Sodium (Na), potassium, iron and calcium in patients with Autosomal dominant polycystic kidney disease among south Indian (Madurai) population.

\section{Methodology}

The study group comprised of hundred clinically proven autosomal dominant polycystic kidney disease (ADPKD) patients (Table 1) of both the sexes in the age group of 10 - 80 years taking treatment in Madurai Government Rajaji hospital and Kidney Transplantation and Research Centre, Madurai, Tamil Nadu, India Ethical clearance was obtained and approval was also obtained from the Institutional Bio-safety committee (IBSC) of Lady Doak College. The age and sex matched healthy subjects were also selected from the general population. The blood samples were collected in EDTA coated tubes from Government Rajaji hospital and Kidney Transplantation and Research centre, Madurai and plasma was separated immediately. The samples were stored at $4^{\circ} \mathrm{C}$.

\subsection{Biochemical Analysis}

The total cholesterol (T. Chol), triglycerides (TGL), high density lipoprotein (HDL), low density lipoprotein (LDL)

Table 1. Prevalence of ADPKD in male and female in the age group of 10 - 80 yr among South Indian population.

\begin{tabular}{cccc}
\hline Age group in years & $\begin{array}{c}\text { Male } \\
(\mathbf{n}=\mathbf{5 3})\end{array}$ & $\begin{array}{c}\text { Female } \\
(\mathbf{n}=\mathbf{4 7})\end{array}$ & $\begin{array}{c}\text { Total population } \\
(\mathbf{n}=\mathbf{1 0 0})\end{array}$ \\
\hline $\mathbf{1 0}-\mathbf{2 0}$ & 4 & 4 & 8 \\
$\mathbf{2 0}-\mathbf{3 0}$ & 6 & 7 & 13 \\
$\mathbf{3 0}-\mathbf{4 0}$ & 14 & 13 & 28 \\
$\mathbf{4 0}-\mathbf{5 0}$ & 15 & 14 & 29 \\
$\mathbf{5 0}-\mathbf{6 0}$ & 7 & 6 & 13 \\
$\mathbf{6 0}-\mathbf{7 0}$ & 5 & 3 & 8 \\
$\mathbf{7 0}-\mathbf{8 0}$ & 2 & - & 2 \\
\hline
\end{tabular}

and very low density lipoprotein (VLDL) were analysed using commercially available kit (Span Diagnostic kit). The levels were measured with Semi Autoanalyzer (Erba, Chem 5X). Sodium, potassium, iron, calcium and iron levels were estimated using Flame Photometer (ELICO, CL 22D) and Atomic Absorption Spectroscopy (AAS) (ELICO, SL 173).

\subsection{Statistical Analysis}

The mean and standard deviation was calculated for ADPKD patients and the control subjects and significant difference between ADPKD patients and the control was calculated by using student $t$ test.

\section{Results}

It was observed that both males (48\%) and females (52\%) are equally affected by ADPKD and that most of the patients fall under the age group of 30 - 50 years. The study also has revealed that $72 \%$ of the patients have high blood pressure (hypertension) (Table 1).

ADPKD patients were observed to have complications like hematuria (12\%), renal calculi $(10 \%)$, urinary tract infection (13\%), diabetic nephropathy (17\%), cardiovascular problems (21\%), renal osteodystrophy (13\%) and anemia (14\%) (Table 2). The results also revealed that most of the patients have hypertension (72\%), diabetes and cardiovascular problems (21\%) and anaemia (14\%). Hence, lipid profile and minerals like calcium, sodium, potassium and iron were studied (Tables 3 and 4).

A significant increase in the level of triglycerides (TGL) ( $<<0.001)$, low density lipoprotein (LDL) $(\mathrm{p}=$ 0.003 ) and very low density lipoprotein (VLDL) ( $<<$ 0.001) were observed in ADPKD patients when compared to the control subjects. There was very little difference in the amount of total cholesterol (T. Chol) (p < 0.05 ) between the patients and control subjects. The level of high density lipoprotein (HDL) was observed to be

Table 2. Analysis of ADPKD associated complications in ADPKD patients among South Indian (Madurai) population.

\begin{tabular}{cc}
\hline Complications & $\begin{array}{c}\text { Occurrence of frequency in } \\
\text { percentage }\end{array}$ \\
\hline Hematuria & $12 \%$ \\
Renal calculi & $10 \%$ \\
Urinary tract infection & $13 \%$ \\
Diabetic nephropathy & $17 \%$ \\
Arthrosclerosis & $21 \%$ \\
Anemia & $14 \%$ \\
Osteodystrophy & $13 \%$ \\
\hline
\end{tabular}


Table 3. Comparative analysis of lipid profile in control subjects and ADPKD subjects.

\begin{tabular}{ccc}
\hline Lipid profile & $\begin{array}{c}\text { Control } \\
(\mathbf{n}=\mathbf{1 0 0})\end{array}$ & $\begin{array}{c}\text { ADPKD Patient } \\
(\mathbf{n}=\mathbf{1 0 0})\end{array}$ \\
\hline T. Chol & $162.14 \pm 3.38$ & $147.87 \pm 4.64$ \\
TGL & $140.87 \pm 3.07$ & $179.32 \pm 7.54$ \\
HDL & $54.54 \pm 1.51$ & $29.608 \pm 0.93$ \\
LDL & $79.31 \pm 3.58$ & $88.23 \pm 3.81$ \\
VLDL & $28.29 \pm 0.60$ & $33.85 \pm 1.54$ \\
\hline
\end{tabular}

Values are mean \pm standard deviation $(\mathrm{mg} / \mathrm{dl})$.

Table 4. Serum/plasma calcium (Ca), sodium (Na) and potassium (K) levels in control subjects and ADPKD patients.

\begin{tabular}{ccc}
\hline Elements & $\begin{array}{c}\text { Control } \\
(\mathbf{n}=\mathbf{1 0 0})\end{array}$ & $\begin{array}{c}\text { ADPKD Patient } \\
(\mathbf{n}=\mathbf{1 0 0})\end{array}$ \\
\hline Calcium (Ca) & $9.33 \pm 0.15$ & $7.94 \pm 0.24$ \\
Sodium (Na) & $133.05 \pm 1.48$ & $98.88 \pm 1.38$ \\
Potassium (K) & $4.29 \pm 0.11$ & $5.91 \pm 0.12$ \\
Iron (Fe) & $60.79 \pm 2.92$ & $24.35 \pm 1.70$ \\
\hline
\end{tabular}

Values are mean \pm standard deviation $(\mathrm{mEq} / \mathrm{dl})$.

significantly decreased $(\mathrm{p}<0.001)$ in ADPKD patients when compared to the control subjects (Table 3 ).

The level of calcium $(\mathrm{Ca})$, sodium $(\mathrm{Na})$, iron $(\mathrm{Fe})$ and potassium $(\mathrm{K})$ revealed the mean plasma calcium and potassium levels to be significantly high $(p<0.001)$ in ADPKD patients. The level of sodium and iron in ADPKD patients were significantly lower $(p<0.001)$ when compared to the control subjects (Table 4).

\section{Discussion}

In the current study, both male and female were observed to be equally affected by autosomal dominant polycystic kidney disease (ADPKD). This might be due to no sexual preponderance in the inheritance. Dyslipidemia, diabetes mellitus, hypertension and cardiovascular disease were also noted among ADPKD patients (Table 2). These complications might be due to low sodium, high calcium and increase in the level of triglycerides (TGL), total cholesterol, low density lipoprotein (LDL) and also decrease in the level of high density lipoprotein (HDL).

Dyslipidemia is reported to be a common complication of progressive kidney disease [27]. Several studies have shown hypercholesterdemia and hypertriglycerdemia to be the risk factors for renal failure [23]. In atherosclerosis, high TGL and low HDL levels have been shown to be associated with risk in developing renal dysfunction [31].

The results also indicate a significant increase in the level of TGL and LDL and significant decrease in the level of HDL in ADPKD patients when compared to the control subjects (Table 2). The total cholesterol level was also found to be normal in patients and it coincides with the results obtained by Dumm et al. [23,25,26]. They have also reported that Ischemic Heart Disease (IHD) and other associated complications of atherosclerosis are the most common causes of death in patients with renal failure (chronic renal failure) [25,26]. Diabetes and hypertension have been reported to be the leading causes for end-stage renal disease (ESRD) in the United States [24]. Trevisian et al. [24] have also stated that hyperlipidemia contributes not only to cardiovascular disease but also to renal progression.

Hypertension has been reported in 50\% - 75\% patients prior to renal insufficiency and is said to be responsible for accelerated decline in renal function [8]. Studies on uraemic patients have shown a multitude of atherogenic risk factors such as hypertension and abnormal lipid metabolism, in addition to diabetes mellitus and hyperparathyroidism [32]. Higher plasma calcium in ADPKD patients than in the control group (Table 4), might be due to cystic calcification and renal osteodystrophy [32]. Cystic calcification might be the consequence of secondary hyper parathyroidism, a recognized complication in patients with renal failure as reported by Coffin et al. (1999) [33].

In chronic kidney disease (CKD), waste products build to high levels when untreated and result in complications such as high blood pressure, anemia and weak bones [23]. The observed increase in the level of serum calcium (Ca) and potassium $(\mathrm{K})$ and decrease in the level of serum sodium ( $\mathrm{Na}$ ) and iron (Fe), might also increase the risk of developing heart and blood vessel diseases that might eventually lead to kidney failure [23]. Iron is needed for healthy blood cells and for overall good health [31]. The kidneys signal the body to make enough red blood cells, and iron helps in making them healthy (National Kidney Foundation).The study has also reported the prevalence of associated complications like diabetic mellitus, hypertension, renal osteodystrophy and anaemia.

From the observations made in the present study it may be concluded that:

1) Abnormalities in basic lipid profile tend to be more frequent in ADPKD and it might constitute a major atherogenic risk factor for the development of diabetes mellitus and cardiovascular disease which might significantly decrease the life span.

2) The changes noted in the levels of calcium, sodium, iron and potassium might be responsible for complications like hyponatremia, hypertension, hypoparathyroidism and renal osteodystrophy in ADPKD patients among south Indian (Madurai) population.

The limitation of the study is that the samples were 
collected only from the patient who came from areas in and around madurai district to take treatment at the Kidney Transplantation \& Research Centre and Government Rajaji Hospital in Madurai.

The future study will be focused on PKD1 and PKD2 gene polymorphism.

\section{REFERENCES}

[1] A. Persu, M. S. Steoenoiu, T. Messiaen, S. Davila, C. Robino, O. El-Khattabi, M. Mourad, S. Horie, O. Feron, J.-L. Balligand, R. Wattiez, Y. Pirson, D. Chauveau, X. M. Lens and O. Devust, "Autosomal Dominant Polycystic Kidney Disease,” Human Molecular Genetics, Vol. 11, No. 3, 2002, pp. 229-241. doi:10.1093/hmg/11.3.229

[2] P. A. Gabow, “Autosomal Dominant Polycystic Kidney Disease," The New England Journal of Medicine, Vol. 329, No. 5, 1993, pp. 332-342. doi:10.1056/NEJM199307293290508

[3] Y. Pei, N. He, K. Wang, M. Kasenda, A. D. Paterson, G. Chan, Y. Liang, J. Roscoe, J. Brissenden, D. Hefferton, P. Parfrey, S. Somlo, S. T. George and P. Hyslop, “A Spectrum of Mutation in Polycystic Kidney Disease-2 (PKD2) Gene from Eight Canadian Kidrede,” Journal of the American Society of Nephrology, Vol. 9, 1998, pp. 18531860.

[4] R. L. Maser, D. Vassmer, B. S. Magenheimer and J. P. Calcet, "Oxidant Stress and Reduced Antioxidant Enzyme Protection in Polycystic Kidney Disease,” Journal of the American Society of Nephrology, Vol. 13, No. 4, 2002, pp. 991-999.

[5] M. Koptides, C. Hadjimichael, P. Koupepidou and C. C. Deltas, "Germinal and Somatic Mutations in the PKD2 Gene of Renal Cysts in Autosomal Dominant Polycystic Kidney Disease,” Human Molecular Genetics, Vol. 8, No. 3, 1999, pp. 509-513. doi:10.1093/hmg/8.3.509

[6] M. Koptides, C. Hadjimichael, P. Koupepidou and C. C. Deltas, "Genetic Evidence for a Trans-Heterozygous Model for Cytogenesis in Autosomal Dominant Polycystic Kidney Disease,” Human Molecular Genetics, Vol. 9, No. 3, 2000, pp. 447-452. doi:10.1093/hmg/9.3.447

[7] B. K. Yoder, X. Hou and L. M. Guay-Woodford, "The Polycystic Kidney Disease Proteins, Polycystin-1, Polycystin-2, Polaris and Cystin, Are Co-Localized in Renal Cilia," Journal of the American Society of Nephrology, Vol. 13, 2002, pp. 2508-2516. doi:10.1097/01.ASN.0000029587.47950.25

[8] B. Tazon-Vega, M. Vilardell, L. Perez-Oller, E. Ars, P. Ruiz, O. Devuyst, X. Lens, Fernandez, P. Llama, J. Ballarin and R. Torra, "Study of Candidate Genes Affecting the Progression of Renal Disease in Autosomal Dominant Polycystic Kidney Disease Type 1,” Nephrology Dialysis Transplantation, Vol. 22, No. 6, 2007, pp. 1567-1577. doi:10.1093/ndt/gfm036

[9] S. Xenophontos, R. Constantinides, T. Hayashi, T. Mochizuki, S. Somlo, A. Pierides and C. C. Delta, "A Translation Frameshift Mutation Induces by a Cytosine Insertion in the Polycystic Kidney Disease 2 gene (PKD2),”
Human Molecular Genetics, Vol. 2, 1997, pp. 949-953. doi:10.1093/hmg/6.6.949

[10] O. Devuyst, A. Persu and M.-T. Vo-Cong, "Autosomal Dominant Polycystic Kidney Disease: Modifier Genes and Endothelial Dysfunction,” Nephrology Dialysis Transplantation, Vol. 18, No. 11, 2003, pp. 2211-2215. doi:10.1093/ndt/gfg351

[11] S. Rossetti, M. B. Consugar, A. B. Chapman, V. E. Torres, L. M. Guay-Woodford, J. J. Grantham, W. M. Bennett, C. M. Meyers, D. L. Walker, K. Bae, Q. Zhang, P. A. Thompson, P. J. Miller and P. C. Harris, "CRISP Consotium: Comparehensive Molecular Diagnostics in Autosomal Dominant Polycystic Kidney Disease,” Journal of the American Society of Nephrology, Vol. 18, 2007, pp. 2143-2160. doi:10.1681/ASN.2006121387

[12] S. Rossetti and P. C. Harris, "Genotype-Phynotype Correlations in Autosomal Dominat and Autosomal Recessive Polycystic Kidney Disease,” Journal of the American Society of Nephrology, Vol. 18, No. 5, 2007, pp. 1374-1380. doi:10.1681/ASN.2007010125

[13] T. J. Watnick, V. E. Torres, M. A. Gandolph, F. Qian, L. F. Onuchic, K. W. Klinger, G. Landes and G. G. Germino, "Somatic Mutation in Individual Liver Cysts Supports a to Hit Model of Cytogenesis in Autosomal Dominant Polycystic Kidney Disease,” Molecular Cell, Vol. 2, 1998, pp. 247-251. doi:10.1016/S1097-2765(00)80135-5

[14] C. Boucher and R. Sandford, "Autosomal Dominant Polycystic Kidney Disease (ADPKD, MIM 173900, PKD1 and PKD2 Genes, Protein Products Known as Polycystin1 and Polycystin-2,” European Journal of Human Genetics, Vol. 12, No. 5, 2004, pp. 347-354. doi:10.1038/sj.ejhg.5201162

[15] R. Torra, M. Viribay, D. Tellaria, C. Badenas, M. Watson, P. Harris, A. Darnell and J. L. San Millan, "Seven Novel Mutations of the PKD2 Gene Families with Autosomal Dominant Polycyctic Kidney Disease,” Kidney International, Vol. 56, No. 1, 1999, pp. 28-33. doi:10.1046/j.1523-1755.1999.00534.x

[16] P. Igarashi and S. Somlo, "Genetics and Pathogenesis of Polycystic Kidney Disease,” Journal of the American Society of Nephrology, Vol. 13, No. 9, 2002, pp. 2384-2398. doi:10.1097/01.ASN.0000028643.17901.42

[17] J. Hughes, C. J. Ward, B. Peral, R. Aspinwall, K. Clak, J. L. San Millan, V. Gamble and P. C. Harris, "The Polycystic Kidney Disease 1 (PKD1) Gene Encodes a Novel Protein with Multible Cell Recognition Domains,” Nature Genetics, Vol. 10, 1995, pp. 151-160. doi:10.1038/ng0695-151

[18] T. C. Burn, T. D. Connors, W. R. Dackowski, L. R. Pertry, T. J. Van Raay, J. M. Millholland, M. Venet, G. Miller, R. M. Hakim, G. M. Landes, K. W. Klinger, F. Qian, et al., "Analysis of the Genomic Sequence for the Autosomal Domiant Polycystic Kideny Disease (PKD1) Gene Predicts the Presence of a Leucine-Rich Repeat," Human Molecular Genetics, Vol. 4, No. 4, 1995, pp. 575582. doi:10.1093/hmg/4.4.575

[19] T. Mochizuki, G. Wu, T. Hayashi, S. Xenophontos, B. Veldhuisen, J. J. Saris, D. Reynolds, Y. Cai, Gabow, A. Pierides, W. Kimberling, M. Breuning, C. Contantinou 
Deltas, D. Peters and S. Somlo, "PKD2, a Gene for Polycystic Kidney Sidease That Encodes an Integral Membrane Protein,” Science, Vol. 272, No. 5266, 1996, pp. 1339-1342. doi:10.1126/science.272.5266.1339

[20] C. J. Ward, M. C. Hogan, S. Rossetti, D. Walker, T. Sneddon, X. Wang, V. Kubly, J. M. Cunningham, R. Bacallao, M. Ishibashi, et al., "The Gene Mutated in Autosomal Recessive Polycystic Kidney Disease Encodes a Large, Receptor-Like Protein,” Nature Genetics, Vol. 30, No. 3, 2002, pp. 259-269. doi:10.1038/ng833

[21] N. Hateboer, B. Veldhusen, D. Peters, M. H. Breuning, M. A. V. Dijk, A. R. Afzal, S. Jeffery, A. K. Saggar-Malik, R. Torra, D. Dimitrakov, I. Matinez, S. Sanz de Castro, M. Krawczak and D. Ravine, "Location of Mutations within the PKD2 Gene Influences Clinical Outcome,” Kidney International, Vol. 57, No. 4, 2000, pp. 1444-1451. doi:10.1046/j.1523-1755.2000.00989.x

[22] M. Ragab and A. Ragab, “Assement of Lipid Profile in Egyptian Children with Chronic Kidney Diseases on Conservative Therapy and Those under Regular Hemodialysis,” Journal of Medical Sciences, Vol. 7, No. 5, 2007, pp. 825-829. doi:10.3923/jms.2007.825.829

[23] N. T. de Gómez Dumm, A. M. Giammona, L. A. Touceda and C. Raimondi, "Lipid Abnormalities in Chronic Renal Failure Patients Undergoing Hemodialysis,” Lipid and Health Diseases, Vol. 2, 2003, pp. 1-6.

[24] R. Trevisan, A. R. Dodesini and G. Lepore, "Lipids and Renal Disease," Journal of the American Chemical Society, Vol. 17, No. S2, 2006, pp. S145-S147.

[25] N. T. de Gómez Dumm, A. M. Giammona, L. A. Touceda and C. Raimondi, "Lipid Abnormalities in Chronic Renal Failure Patients Undergoing Hemodialysis,” Medicina (Buenos Aires), Vol. 61, No. 2, 2001, pp. 142-146.

[26] N. T. de Gómez Dumm, A. M. Giammona and L. A.
Touceda, "Variations in the Lipid Profile of Patients with Chronic Renal Failure Treated with Pyridoxine,” Lipid and Health Diseases, Vol. 2, 2003, p. 7.

[27] A. Cases and E. Coll, "Dyslipidemia and the Progression of Renal Disease in Chronic Renal Failure Patients," Kidney International, Vol. 68, No. 99, 2005, pp. S87-S93. doi:10.1111/j.1523-1755.2005.09916.x

[28] L. P. Sullivan, D. P. Wallace and J. J. Grantham, "Epithelial Transport in Polycystic Kidney Disease,” Physiological Reviews, Vol. 78, No. 4, 1998, pp. 1165-1191.

[29] J. J. Grantham and P. J. Calvet, "Polycystein-2, the Protein Mutated in Autosomal Dominant Polycystic Kidney Disease (ADPKD), Is a Ca2+ Permeable Nonselective Cation Chennel," Proceedings of the National Academy of Sciences of the United States of America, Vol. 98, No. 3, 2001, pp. 790-792. doi:10.1073/pnas.98.3.790

[30] R. Constantinides, S. Xenophoutos, P. Neophyton, S. Nomura, A. Pierides and C. C. Deltas, "New Amino Acid Polymorphism, Ala/Val4058, in Exon 45 of the Polycystic Kidney Disease 1 Gene,” Human Genetics, Vol. 99, No. 5, 1997, pp. 644-647. doi:10.1007/s004390050421

[31] P. Muntner, J. Coresh, J. C. Smith, et al., "Plasma Lipid and Risk of Developing Renal Dysfunction: The Artherosclerosis Risk in Communities," Kidney International, Vol. 58, No. 1, 2000, pp. 293-301. doi:10.1046/j.1523-1755.2000.00165.x

[32] A. E. Grzegprzewska and M. Mlot, "Serum Osteoprotegrin Level Is Lower in Peritoneal Dialysis Patients than in Hemodialysi Ones,” Annal Acad Medcae Bialosto, 2004, p. 49.

[33] B. Coffin, Hadengue, F. Degos and J.-P. Benhamou, "Calcified Hepatic and Renal Cysts in Adult Dominant Polycystic Kidney Disease,” Digestive Diseases and Sciences, Vol. 15, No. 9, 1999. 